\title{
Multidisciplinary treatment for colorectal liver metastases in elderly patients
}

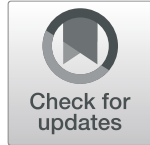

Taigo Hata ${ }^{1,2}$, Yoshihiro Mise ${ }^{1,3}$, Yoshihiro Ono ${ }^{1}$, Takafumi Sato ${ }^{1}$, Yosuke Inoue ${ }^{1}$, Hiromichi Ito ${ }^{1}$, Yu Takahashi', Katsuhiko Yanaga ${ }^{2}$ and Akio Saiura ${ }^{1,3^{*}}$

\begin{abstract}
Background: Limited data describe the therapeutic practice and outcomes of colorectal liver metastases (CRLMs) in elderly patients. We aimed to evaluate the impact of age on multidisciplinary treatment for CRLMs.

Methods: We reviewed treatment and outcomes for patients in different age groups who underwent initial hepatectomy for CRLMs from 2004 through 2012.

Results: We studied 462 patients who were divided into three groups by age: $\leq 64$ years $(n=265)$, 65-74 years ( $n$ $=151$ ), and $\geq 75$ years $(n=46)$. The rate of major hepatectomy and incidence of postoperative complications did not differ between groups. Adjuvant chemotherapy was used less in the $\geq 75$-year group (19.6\%) than that in the $\leq 64$ (54.3\%) or 65-74 age group (43.5\%). Repeat hepatectomy for liver recurrence was performed less in the $\geq 75$ year group (35\%) than in the $\leq 64(57 \%)$ or $65-74(66 \%)$ age group. The 5 -year disease-specific survival (DSS) rate of $44.2 \%$ in the $\geq 75$-year group was lower than in the $\leq 64$ (59.0\%) or 65-74 (64.7\%) age group. Multivariate analysis revealed age $\geq 75$ years was an independent predictor of poor DSS.
\end{abstract}

Conclusions: Liver resection for CRLMs can be performed safely in elderly patients. However, repeat resection for recurrence are performed less frequently in the elderly, which may lead to the poorer disease-specific prognosis.

Keywords: Hepatectomy, Colorectal cancer, Elderly

\section{Introduction}

With the rapid aging of the society, medical services for elderly patients have become more important in many developed countries. In Japan, the prevalence of colorectal cancer has continued to increase with the development of a super-aging society in which the population of those $\geq 65$ years exceeds $21 \%$, while the age-adjusted incidence rate of colorectal cancer has not changed [1-3]. Consequently, the treatment strategy for liver metastases, which are accompanied by more than $50 \%$ of

\footnotetext{
*Correspondence: a-saiura@juntendo.ac.jp

1 Department of Hepatobiliary Pancreatic Surgery, Cancer Institute Hospital, Japanese Foundation for Cancer Research, 3-8-31 Ariake, Koto-ku, Tokyo 135-8550, Japan

${ }^{3}$ Department of Hepatobiliary-Pancreatic Surgery, Juntendo University School of Medicine, 3-1-3 Hongo, Bunkyo-ku, Tokyo 113-8431, Japan

Full list of author information is available at the end of the article
}

colorectal cancer patients, has become a greater concern in elderly patients [4-17].

Hepatectomy is accepted as a cornerstone of treatment for colorectal liver metastases (CRLMs). Reports of encouraging long-term outcomes after surgery in the elderly with CRLMs have been published, with 5-year survival rates between 21 and 44\% [4, 7, 14]. However, surgical treatment alone is not enough, and a multidisciplinary approach including repeat resection is now indispensable to achieve improved outcome for the treatment for CRLMs. Perioperative chemotherapy improves recurrence-free survival (RFS) in patients with CRLMs [18, 19], and aggressive repeat hepatectomy is also an important option because the first relapse after initial hepatectomy does not reflect cancer-related survival in patients with CRLMs [20-23]. So far, little is 
known about the relationship between advanced age and the prevalence of multidisciplinary treatment, such as perioperative chemotherapy or aggressive treatment for recurrence after initial hepatectomy.

The aim of this study was to investigate the impact of patient age on the feasibility of a multidisciplinary approach to CRLMs in a high-volume hepato-pancreatobiliary center in Japan. We examined the safety of initial hepatectomy, the prevalence of perioperative chemotherapy, recurrence pattern after initial hepatectomy, and the prevalence of repeat resection for the recurrence, in relation to the age.

\section{Material and methods}

The prospectively maintained database of the Cancer Institute Hospital, Tokyo, Japan, was queried to identify patients who underwent initial hepatectomy for CRLMs at this hospital from January 2004 through December 2012. We excluded patients who underwent R2 resection. During the study period, 462 patients underwent initial hepatectomy for CRLMs with curative intent. Of these, 265 patients $(57.4 \%)$ were $\leq 64$ years of age with a median of 56 years; 151 patients (32.7\%) were 65-74 years with a mean age of 68 years, and the other 46 patients (9.9\%) were $\geq 75$ years with a median age of 80 years. The study population was divided into three age groups: $\leq 64$ years, $65-74$ years, and $\geq 75$ years of age. Baseline characteristics, perioperative course, and long-term outcomes were compared retrospectively between the three groups.

The Institutional Review Board of the Cancer Institute Hospital approved this study (Protocol 2018-1033).

\section{Indications for hepatectomy for CRLMs}

In our institute, indications for resection of CRLMs during January 2004 through December 2012, period consisted of (1) no comorbid conditions that preclude hepatic resection, (2) all liver tumors that were amenable to resection would have a clear margin, leaving at least $30 \%$ of noncancerous remnant liver without a potentially ischemic or congested area, and (3) no unresectable extrahepatic tumors. The indications for repeat hepatectomy for liver recurrence were the same as those for initial hepatectomy. No age restriction was set for initial or repeat hepatectomy as long as patients met the above criteria.

Routine use of preoperative chemotherapy was not adopted until 2010. After 2010, preoperative chemotherapy was routinely performed for patients with $\geq 4$ CRLMs or those with CRLMs $>50 \mathrm{~mm}$ or those with resectable extrahepatic metastases by imaging studies [24].

\section{Surgical procedure and postoperative outcomes}

Parenchymal-sparing hepatectomy was the standard procedure regardless of the number or size of CRLMs.
Major hepatectomy, which was defined as resection of $\geq$ 3 segments, was performed only when CRLMs were close to major Glisson's pedicles. Following laparotomy and liver mobilization, fundamental intraoperative ultrasonography was performed to confirm the tumors detected by preoperative imaging and to search for new occult lesions. Resecting of all the tumors were intended, including newly detected nodules and disappearing CRLMs by preoperative imaging. Liver transections were performed by the crushing technique using the LigaSure vessel sealing system (Valleylab, Boulder, CO, USA), as reported previously [25]. Surgical margins were measured from the resected specimens. A positive surgical margin was defined as microscopic evidence of tumor at the resection margin.

The severity of postoperative complications was assessed according to the Clavien-Dindo classification; grade IIIa or worse was defined as a major complication. Any complications that developed within 90 days after the operation were included [26].

\section{Postoperative follow-up}

Patient follow-up consisted of measuring serum tumor markers (carcinoembryonic antigen and carbohydrate antigen) at every visit as well as enhanced computed tomography every 3-6 months. Although adjuvant chemotherapy was not routinely administered, it was given to (1) patients who were included in clinical studies, (2) patients who underwent simultaneous resection of advanced primary disease, and (3) patients who had advanced CRLMs judged by a multidisciplinary team.

\section{Statistical analysis}

Associations between variables with categorical data were sought using either Fisher's exact test or Pearson's chi-squared test. The Mann-Whitney's $U$ test was applied to continuous variables between the three groups. Survival curves were generated by the Kaplan-Meier method, and comparisons between the groups were performed using a log-rank test. Overall survival (OS), disease-specific survival (DSS), and recurrence-free survival (RFS) were defined as the interval from the date of primary hepatectomy to the date of all death, death attributed to colorectal cancer, and recurrence, respectively. Statistical significance was assessed using a twotailed test across $p<0.05$. All the statistical analyses were performed using the JMP software, version 10 (SAS Institute Inc., Cary, NC, USA).

\section{Results}

Patient characteristics

Baseline characteristics of the three groups are summarized in Table 1 . The older age group of $\geq 75$ years had 
Table 1 Characteristics of patients with CRLMs in the three age groups

\begin{tabular}{|c|c|c|c|c|}
\hline \multirow[t]{2}{*}{ Variable } & $\leq 64$ years & $65-74$ years & $\geq 75$ years & \multirow[t]{2}{*}{$p$ value } \\
\hline & $(n=265)$ & $(n=151)$ & $(n=46)$ & \\
\hline \multicolumn{5}{|l|}{ Patients } \\
\hline Age, year & $56(30-64)$ & $68(65-74)$ & $80(75-85)$ & \\
\hline Sex, male, $n(\%)$ & $162(61.1)$ & $104(68.9)$ & $33(71.7)$ & 0.163 \\
\hline \multicolumn{5}{|l|}{ Primary tumor } \\
\hline \multicolumn{5}{|l|}{ Tumor differentiation, $n(\%)$} \\
\hline Well or moderately & $244(92.1)$ & $134(88.7)$ & $41(89.1)$ & 0.991 \\
\hline Poorly & $6(4.0)$ & $3(2.0)$ & $1(2.2)$ & \\
\hline Node, positive, $n(\%)$ & $183(69.6)$ & $102(68.5)$ & $23(51.1)$ & 0.056 \\
\hline \multicolumn{5}{|l|}{ Comorbidity } \\
\hline Hypertension, $n$ (\%) & $46(17.6)$ & $37(24.5)$ & $19(41.3)$ & 0.001 \\
\hline Diabetes mellitus, $n$ (\%) & $21(7.9)$ & $26(17.2)$ & $6(13.0)$ & 0.016 \\
\hline CNS conditions, $n(\%)$ & $7(2.6)$ & $8(2.3)$ & $4(8.7)$ & 0.108 \\
\hline Pulmonary disease, $n(\%)$ & $11(4.2)$ & $6(4.0)$ & $3(6.5)$ & 0.740 \\
\hline Cardiovascular disease, $n$ (\%) & $9(3.4)$ & $11(7.3)$ & $8(17.4)$ & 0.0009 \\
\hline \multicolumn{5}{|l|}{ Liver metastases } \\
\hline Synchronous with primary tumor, $n(\%)$ & $151(57.0)$ & $82(54.3)$ & $23(50)$ & 0.642 \\
\hline Synchronous resection, $n$ (\%) & 97 (36.6) & $48(31.8)$ & $14(30.4)$ & 0.510 \\
\hline Serum CEA, ng/mL & $6.6(0.5-2606)$ & $7.4(0.9-7828)$ & $9.1(1.2-3097)$ & 0.638 \\
\hline Size, $\mathrm{cm}$ & $2.2(0.3-19.0)$ & $2.5(0.2-10.5)$ & $3.0(1.1-10.0)$ & 0.149 \\
\hline Number & $2(1-31)$ & $2(1-33)$ & $2(1-23)$ & 0.041 \\
\hline Extrahepatic metastasis, $n(\%)$ & 46 (19.3) & $17(12.5)$ & $6(14.3)$ & 0.212 \\
\hline
\end{tabular}

Continuous data expressed as median (range)

CRLMs colorectal cancer liver metastases; CNS central nervous system; CEA carcinoembryonic antigen

more frequent hypertension and cardiovascular disease compared to the other groups.

\section{Perioperative chemotherapy}

Table 2 summarizes the perioperative course of the three age groups. No differences were found in the rate of administration of preoperative chemotherapy before hepatectomy. However, fewer patients $\geq 75$ years of age (19.6\%) received adjuvant chemotherapy after hepatectomy compared to the age groups of $\leq 64$ years $(54.3 \%)$ or $65-74$ years $(43.5 \%, p<0.001)$.

\section{Surgical outcomes}

The rate of major hepatectomy was not different between the three groups. Despite the same extent of surgery, the amount of blood loss was smallest in the $\geq$ 75 year group. No differences were found between the groups in the incidence of major complications.

\section{Recurrence pattern after initial hepatectomy}

Figure 1 shows the recurrence sites in the 329 patients (71.2\%) who developed recurrence after the initial hepatectomy. No differences were found in the incidence of liver recurrence between the three groups $(p=0.17)$.
However, aged $\geq 75$ years had less frequent repeat hepatectomy for liver recurrence $(8 / 20[35 \%])$ as compared to the proportion in the age group of $\leq 64$ years $(67 / 118$ [57\%]) or 65-74 years $(45 / 68$ [66\%] $)(p=0.0436)$. Among patients who had recurrence in $\geq 75$ year group, DSS was better in those who had repeat resection for recurrence than that in those without repeat resection $(p$ $=0.0024$ ).

No 90-day mortality was found after repeat hepatectomy in any group.

\section{Long-term outcomes}

Figure 2a, b, and c demonstrates RFS, OS, and DSS curves of the three groups, respectively. The 3-year and 5 -year RFS rate of the $\geq 75$ year group $(43.5 \% / 37.9 \%)$ were lower than those in the $\leq 64(29.8 \% / 28.4 \%)$ or $65-$ 74 groups $(34.4 \% / 31.7 \%, p=0.4914)$. The 3 -year and 5year OS rates of the $\geq 75$ year group $(53.5 \% / 44.2 \%)$ were lower than those in the $\leq 64(69.5 \% / 59.0 \%)$ or $65-74$ groups $(77.1 \% / 64.7 \%, p=0.0229)$. Furthermore, the 3year and 5-year DSS rates of the $\geq 75$ year group (53.5\%/ $44.2 \%)$ were lower than those in the $\leq 64$ (69.5\%/59.0\%) or $65-74$ groups $(77.1 \% / 64.7 \%, p=0.0187)$. The rates of mortality not related to the cancer in the $<65,65-74, \geq$ 
Table 2 Perioperative course of patients with CRLMs in the three age groups

\begin{tabular}{|c|c|c|c|c|}
\hline \multirow[t]{2}{*}{ Variable } & $\leq 64$ years & $65-74$ years & $\geq 75$ years & \multirow[t]{2}{*}{$p$ value } \\
\hline & $(n=265)$ & $(n=151)$ & $(n=46)$ & \\
\hline Major hepatectomy, n (\%) & $53(20.0)$ & $36(23.8)$ & $9(19.6)$ & 0.628 \\
\hline Operation time, min & $305.0(60-953)$ & $275.0(95-695)$ & $263.0(115-810)$ & 0.194 \\
\hline Blood loss, ml & $390(20-2640)$ & $300(10-6530)$ & $265(5-1910)$ & 0.023 \\
\hline Surgical margin: positive, $n(\%)$ & $15(5.7)$ & $8(5.3)$ & $2(4.3)$ & 0.934 \\
\hline Preoperative chemotherapy, $n$ (\%) & $107(40.4)$ & $47(31.1)$ & $12(26.1)$ & 0.057 \\
\hline Adjuvant chemotherapy, $n$ (\%) & $144(54.3)$ & $65(43.5)$ & $9(19.6)$ & $<0.001$ \\
\hline \multicolumn{5}{|l|}{ Complication } \\
\hline Major complications, $n$ (\%) & $17(6.4)$ & $9(6.0)$ & $3(6.5)$ & 0.981 \\
\hline Biliary leakage, $n(\%)$ & $9(3.4)$ & $6(4.0)$ & $2(4.4)$ & 0.926 \\
\hline Intraabdominal hemorrhage, $n(\%)$ & $3(1.1)$ & $2(1.3)$ & $1(2.1)$ & 0.847 \\
\hline Surgical site infection, $n(\%)$ & $24(9.1)$ & $14(9.3)$ & $3(6.5)$ & 0.837 \\
\hline Postoperative hospital stay, days & $14(5-160)$ & $15(8-372)$ & $15(8-45)$ & 0.338 \\
\hline Mortality, $n$ & 0 & 0 & 0 & \\
\hline
\end{tabular}

Continuous data expressed as median (range)

CRLMs colorectal cancer liver metastases.

75 groups were $4.2 \%(11 / 265), 4.6 \%(7 / 151)$, and $8.7 \%$ $(4 / 46)$, respectively $(p=0.4080)$.

\section{Multivariate analysis of prognostic factors of DSS}

Table 3 summarizes the results of univariate and multivariate analyses of clinical factors to predict impaired DSS in the study population. Age $\geq 75$ years was found to be an independent prognostic factor of DSS ( $p=$ 0.0005 , hazard ratio 3.23 , confidence interval 1.72-5.75).

\section{Discussion}

We assessed the relationship between advanced age and the outcome of multidisciplinary treatment for CRLMs. The study revealed that cancer-related survival in patients $\geq 75$ years was significantly impaired, which may have been caused by the lower rate of repeat hepatectomy for liver recurrence in the older patients. However, liver resection can provide an acceptable prognosis with short-term outcomes comparable to those of the younger patients.

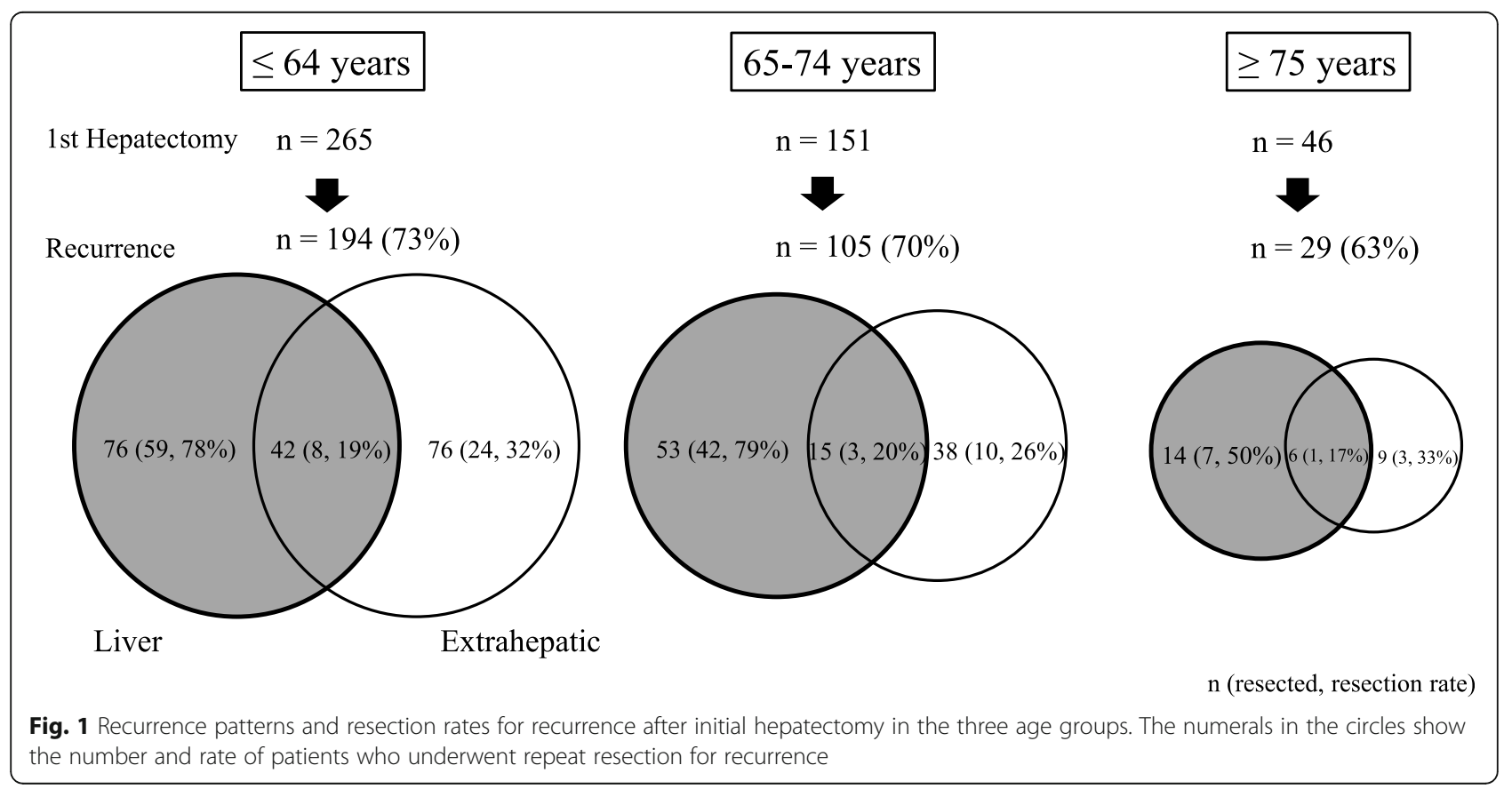



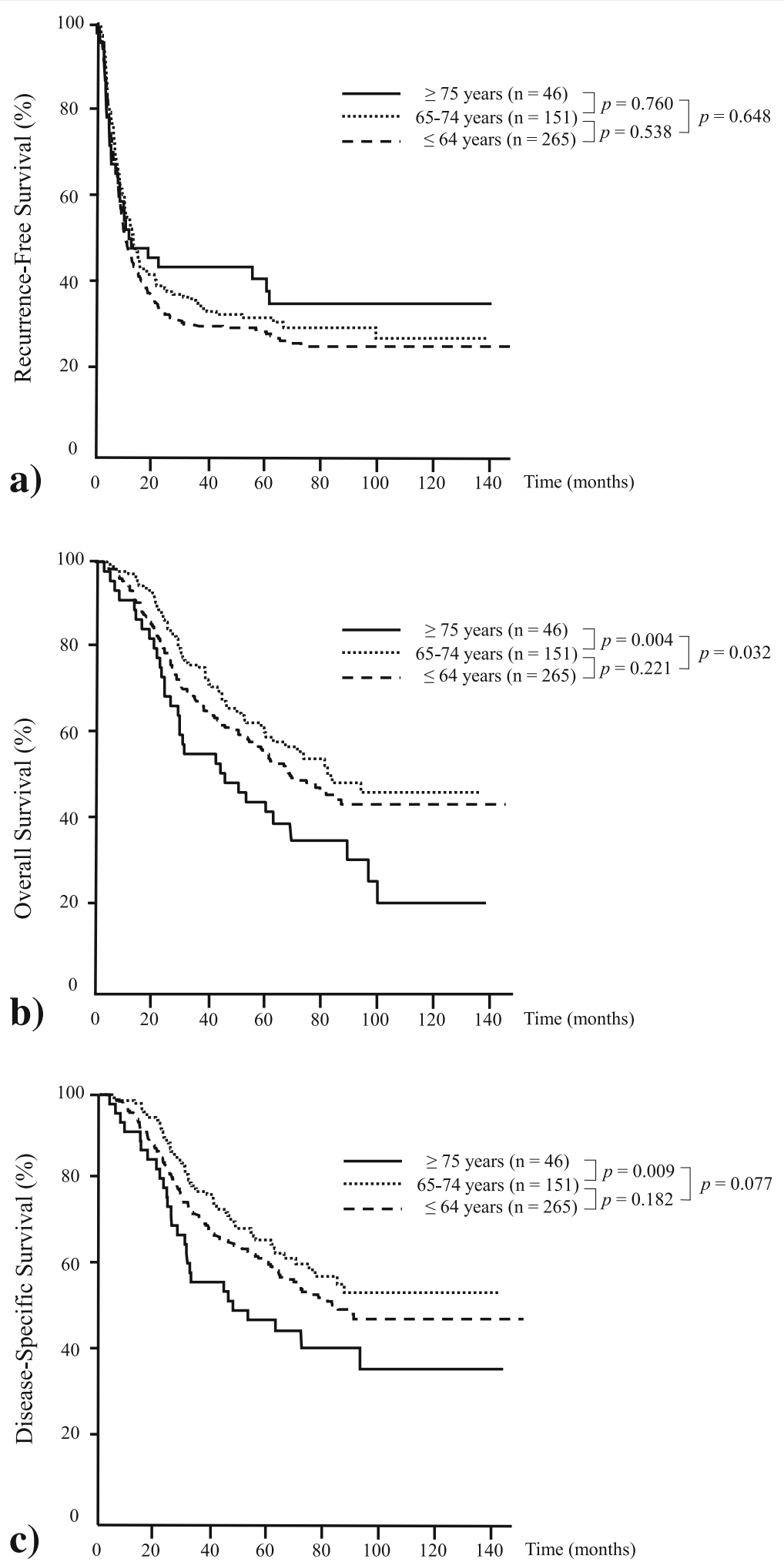

Fig. 2 Survival curves in the three age groups. a Recurrence-free survival. b Overall survival. c Disease-specific survival 
Table 3 Univariate and multivariate analysis of factors to predict impaired DSS in oldest patients with CLRMs

\begin{tabular}{|c|c|c|c|c|}
\hline \multirow[t]{2}{*}{ Variable } & & \multirow{2}{*}{$\begin{array}{l}\text { Univariate analysis } \\
p \text { value }\end{array}$} & \multicolumn{2}{|c|}{ Multivariate analysis } \\
\hline & & & $p$ value & HR $(95 \% \mathrm{Cl})$ \\
\hline \multirow[t]{2}{*}{ Patients } & Sex, male & 0.124 & & \\
\hline & Age $\geq 75$ & 0.038 & 0.0005 & $3.231(1.725-5.758)$ \\
\hline \multirow[t]{2}{*}{ Preoperative factors } & $C E A \geq 5$ & 0.037 & & \\
\hline & No preoperative chemotherapy & 0.011 & & \\
\hline \multirow[t]{3}{*}{ Primary tumor } & Site: rectum & 0.245 & & \\
\hline & N positive & $<0.01$ & & \\
\hline & Tumor differentiation: poorly & 0.0061 & & \\
\hline \multirow[t]{3}{*}{ Liver metastases } & Synchronous & 0.932 & & \\
\hline & Size $\geq 2 \mathrm{~cm}$ & 0.0002 & & \\
\hline & Number $\geq 2$ & $<0.01$ & & \\
\hline \multirow[t]{5}{*}{ Perioperative factors } & Non-PSH approach & 0.049 & & \\
\hline & Operative time $>180 \mathrm{~min}$ & 0.004 & & \\
\hline & Blood loss $>500$ & 0.006 & & \\
\hline & Surgical margin: positive & 0.0003 & & \\
\hline & Major complications & 0.001 & & \\
\hline \multirow[t]{2}{*}{ Postoperative factors } & DFI from 1st hepatectomy $<1$ year & $<0.01$ & $<0.01$ & $2.951(1.778-5.163)$ \\
\hline & No postoperative chemotherapy & 0.94 & & \\
\hline
\end{tabular}

CRLMs colorectal cancer liver metastases; DSS disease-specific survival; N lymph node; PSH parenchymal-sparing hepatectomy; DFI disease-free interval

In the current study, the 5-year DSS rate in the elderly group (44.2\%) was significantly lower than that of the younger patients. Multivariate analysis of the study population revealed that age $\geq 75$ years was an independent predictor for impaired DSS. There are many reports assessing the prognostic benefit of hepatectomy in the elderly $[5,7,9,11,14,16,17]$. However, the mixed reporting of overall and cancer-specific survival has made it difficult to interpret the long-term outcome. To investigate the differences in chronological age, DSS needs to be assessed because OS is impaired in the elderly as a result of the more limited life expectancy than in younger patients. Brudvik et al. well demonstrated a significant difference between OS and DSS in the elderly (80-89 years of age) and the prognostic benefit of hepatectomy by showing that the gap between the 5 -year survival of the age-matched national population (66.3\%) and 5-year DSS rate (43.1\%) decreases compared with the 5-year OS rate (32.5\%) after hepatectomy [17].

Analysis of recurrence after initial hepatectomy revealed that repeat hepatectomy was performed less in the elderly group with liver recurrence, although the recurrence pattern was not different between the groups. This result indicated that in clinical practice, aggressive treatment for recurrence was reserved, even when indication criteria for repeat hepatectomy were met, regardless of the patient's age. The major strength of this study was the detailed analysis of treatment for recurrence after initial hepatectomy, which revealed the cause of the poorer disease-specific prognosis in the elderly having CRLMs. Repeat hepatectomy is one of the essential treatments for CRLMs, because the biology of colorectal cancer is unique; the recurrence after the initial surgery is not directly associated with cancer-related death. Oba et al. demonstrated that the time to development of unresectable recurrence after initial surgery is a better surrogates prognosis than RFS in patients undergoing surgery for CRLMs [23]. The current study revealed that repeat hepatectomy was safely performed without mortality even in the elderly, which is consistent with a previous report showing no mortality in 114 patients $\geq 70$ years having repeat resection after initial hepatectomy [7]. The results of the current study confirm that aggressive repeat resection is a feasible option to improve survival in well-selected older patients having recurrence after initial hepatectomy. The next step is to elucidate the indication process for repeat hepatectomy in the elderly so as to optimize patient selection for the aggressive treatment.

The prevalence of adjuvant chemotherapy after initial hepatectomy was lower in the elderly group than in the younger groups. This result may be another cause of poorer DSS in the elderly in this study. Adam et al. demonstrated that no adjuvant chemotherapy after initial hepatectomy was an independent predictor of reduced OS in the patients $\geq 70$ years undergoing hepatectomy for CRLMs [7]. However, their analysis of OS rather than DSS has made it difficult to interpret the result 
because senile weakness intolerant to adjuvant chemotherapy may have been directly associated with cancerunrelated death in their assessment. Although administration of adjuvant chemotherapy after hepatectomy was not selected as a prognostic factor of DSS in univariate and multivariate analysis in the current study, a recent randomized trial demonstrated that adjuvant chemotherapy improves RFS in patients undergoing hepatectomy for CRLMs [27]. Additional studies are needed to investigate the prognostic impact of adjuvant chemotherapy, especially in older patients for whom the balance between therapeutic effect and toxicity is of great importance.

Initial and repeat hepatectomies were safely performed in the elderly group without mortality in the current study. No differences were found in other short-term outcomes, such as the prevalence of major complications and the length of hospital stay after initial hepatectomy, even when surgical procedures were similar among the groups. We assume that the favorable short-term outcomes in the elderly were attributable to the low rate of major hepatectomy (19.6\%) in this study, considering the results of previous reports. Although there is some discrepancy in the definition of "the elder" and "mortality," previous large series of population-based or multicenter studies demonstrated the rates of major hepatectomy as $37.5 \%$ to $56 \%$ in the elderly. Consequently, the mortality rate was reportedly as high as $3.8 \%$ to $8 \%[7,12,14]$. The parenchymal-sparing approach is now accepted as the standard procedure for resection of CRLMs to achieve better short- and long-term outcomes [28-30]. Greater concern should be taken to choose less invasive parenchymal-sparing hepatectomy in the elderly who are physically weak because of senile decay. Referral to a specialist hepatobiliary surgery team is favorable to avoid major hepatectomy because parenchymal-sparing hepatectomy for tumors in difficult locations is technically demanding [31].

The limitations of this study include its retrospective nature and the small number of patients in a singlecenter experience. As mentioned above, the selection process for repeat hepatectomy was not clear because of the limited data. In addition, the detailed data of administration of preoperative or adjuvant chemotherapy were not available in this study. However, the detailed analysis of the recurrence pattern and the treatment for recurrence would not have been possible using population-based data [12, 14]. In addition, although population-based analyses are said to better describe the outcomes achieved in routine practice [14], the trend in centralization of high-risk surgery is associated with improved short- as well as long-term outcomes [32-42]. Considering much better outcomes reported from highvolume liver centers $[20,43-45]$, the results demonstrated in the current study may reflect ideal practice in the near future when centralization is optimized for older patients with CRLMs undergoing hepatectomy.

In conclusion, in patients $\geq 75$ years undergoing hepatectomy for CRLMs, cancer-related survival was significantly impaired, which may have been caused by the lower rate of repeat hepatectomy for recurrence in this population. However, liver resection can provide an acceptable prognosis with short-term outcomes comparable to those of the younger patients.

\section{Acknowledgements}

Not applicable.

\section{Authors' contributions}

TH and YM participated in the literature search, drafting of the manuscript, and data interpretation creating the tables and performed the statistical analysis. AS conceived of the study and helped in the coordination and drafting of the manuscript. All authors read and approved the final manuscript. The manuscript has not been submitted to more than one journal for simultaneous consideration.

\section{Funding}

This research did not receive any specific grant from any funding agency in the public, commercial, or not-for-profit sectors.

\section{Availability of data and materials}

The datasets used and/or analyzed during the current study are available from the corresponding author on reasonable request.

\section{Ethics approval and consent to participate}

This study was approved by the Institutional Review Board of the Cancer Institute Hospital of Japanese Foundation for Cancer Research (Tokyo, Japan). The patients' concern has not been needed because of the retrospective nature of the study.

\section{Consent for publication}

Not applicable.

\section{Competing interests}

The authors declare that they have no competing interests.

\section{Author details}

${ }^{1}$ Department of Hepatobiliary Pancreatic Surgery, Cancer Institute Hospital, Japanese Foundation for Cancer Research, 3-8-31 Ariake, Koto-ku, Tokyo 135-8550, Japan. ${ }^{2}$ Department of Surgery, Jikei University School of Medicine, 3-19-18 Nishi-shinbashi, Minato-ku, Tokyo 105-8471, Japan. ${ }^{3}$ Department of Hepatobiliary-Pancreatic Surgery, Juntendo University School of Medicine, 3-1-3 Hongo, Bunkyo-ku, Tokyo 113-8431, Japan.

Received: 2 March 2020 Accepted: 7 July 2020

Published online: 17 July 2020

\section{References}

1. Kochi $M$, Hinoi $T$, Niitsu $H$, Ohdan $H$, Konishi $F$, Kinugasa $Y$, et al. Risk factors for postoperative pneumonia in elderly patients with colorectal cancer: a sub-analysis of a large, multicenter, case-control study in Japan. Surgery today. 2018;48:756-64

2. Yearbook JS. Statistics Bureau MolAaC. Japan. 2016;2016.

3. Cancer Statistics in Japan. Foundation for promotion of cancer research (FPCR). National Cancer Center TEBotCSiJ. 2014;2015.

4. Zacharias T, Jaeck D, Oussoultzoglou E, Bachellier P, Weber JC. First and repeat resection of colorectal liver metastases in elderly patients. Ann Surg. 2004;240:858-65.

5. Nagano Y, Nojiri K, Matsuo K, Tanaka K, Togo S, Ike H, et al. The impact of advanced age on hepatic resection of colorectal liver metastases. J Am Coll Surg. 2005;201:511-6. 
6. Mann CD, Neal CP, Pattenden CJ, Metcalfe MS, Garcea G, Dennison AR, et al. Major resection of hepatic colorectal liver metastases in elderly patients - an aggressive approach is justified. Eur J Surg Oncol. 2008;34:428-32.

7. Adam R, Frilling A, Elias D, Laurent C, Ramos E, Capussotti L, et al. Liver resection of colorectal metastases in elderly patients. Br J Surg. 2010;97:366-76.

8. Power DG, Lichtman SM. Resection of colorectal liver metastases: only for younger patients? The Lancet Oncol. 2010;11:116.

9. Cannon RM, Martin RC, Callender GG, McMasters KM, Scoggins CR. Safety and efficacy of hepatectomy for colorectal metastases in the elderly. J Surg Oncol. 2011;104:804-8.

10. Kulik U, Framke T, Grosshennig A, Ceylan A, Bektas H, Klempnauer J, et al. Liver resection of colorectal liver metastases in elderly patients. World J Surg. 2011;35:2063-72.

11. Cook EJ, Welsh FK, Chandrakumaran K, John TG, Rees M. Resection of colorectal liver metastases in the elderly: does age matter? Colorectal Dis. 2012;14:1210-6

12. Tzeng CW, Cooper AB, Vauthey JN, Curley SA, Aloia TA. Predictors of morbidity and mortality after hepatectomy in elderly patients: analysis of 7621 NSQIP patients. HPB (Oxford). 2014;16:459-68.

13. Yang S, Alibhai SM, Kennedy ED, El-Sedfy A, Dixon M, Coburn N, et al. Optimal management of colorectal liver metastases in older patients: a decision analysis. HPB (Oxford). 2014;16:1031-42.

14. Booth CM, Nanji S, Wei X, Mackillop WJ. Management and outcome of colorectal cancer liver metastases in elderly patients: a population-based study. JAMA Oncol. 2015;1:1111-9.

15. Schmidt T, Strowitzki MJ, Reissfelder C, Rahbari NN, Nienhueser H, Bruckner T, et al. Influence of age on resection of colorectal liver metastases. J surg oncol. 2015;111:729-39.

16. Bell R, Pandanaboyana S, Nisar S, Upasani V, Toogood G, Lodge JP, et al. The impact of advancing age on recurrence and survival following major hepatectomy for colorectal liver metastases. J Gastrointest Surg. 2017;21: 266-74

17. Brudvik KW, Rosok B, Naresh U, Yaqub S, Fretland AA, Labori K, et al. Survival after resection of colorectal liver metastases in octogenarians and sexagenarians compared to their respective age-matched national population. Hepatobiliary Surg Nutr. 2018;7:234-41.

18. Nordlinger B, Sorbye H, Glimelius B, Poston GJ, Schlag PM, Rougier P, et al. Perioperative chemotherapy with FOLFOX4 and surgery versus surgery alone for resectable liver metastases from colorectal cancer (EORTC Intergroup trial 40983): a randomised controlled trial. Lancet. 2008;371:1007-16.

19. Van Cutsem E, Cervantes A, Nordlinger B, Arnold D. Metastatic colorectal cancer: ESMO Clinical Practice Guidelines for diagnosis, treatment and follow-up. Ann Oncol. 2014:25 Suppl 3:iii1-9.

20. Adam R, Pascal G, Azoulay D, Tanaka K, Castaing D, Bismuth H. Liver resection for colorectal metastases: the third hepatectomy. Ann surg. 2003; 238:871-883; discussion 883-74

21. Andreou A, Brouquet A, Abdalla EK, Aloia TA, Curley SA, Vauthey JN. Repeat hepatectomy for recurrent colorectal liver metastases is associated with a high survival rate. HPB (Oxford). 2011:13:774-82.

22. Jones RP, Jackson R, Dunne DF, Malik HZ, Fenwick SW, Poston GJ, et al. Systematic review and meta-analysis of follow-up after hepatectomy for colorectal liver metastases. Br J Surg. 2012;99:477-86.

23. Oba M, Hasegawa $K$, Matsuyama $Y$, Shindoh J, Mise $Y$, Aoki T, et al. Discrepancy between recurrence-free survival and overall survival in patients with resectable colorectal liver metastases: a potential surrogate endpoint for time to surgical failure. Ann surg oncol. 2014;21:1817-24.

24. Oba A, Mise $Y$, Ito H, Hiratsuka M, Inoue $Y$, Ishizawa $T$, et al. Clinical implications of disappearing colorectal liver metastases have changed in the era of hepatocyte-specific MRI and contrast-enhanced intraoperative ultrasonography. HPB (Oxford). 2018;20:708-14.

25. Saiura A, Yamamoto J, Koga R, Seki M, Yamaguchi T. Liver transection using the LigaSure sealing system. HPB (Oxford). 2008;10:239-43.

26. Mise Y, Vauthey JN, Zimmitti G, Parker NH, Conrad C, Aloia TA, et al. Ninetyday postoperative mortality is a legitimate measure of hepatopancreatobiliary surgical quality. Ann surg. 2015;262:1071-8.

27. Hasegawa K, Saiura A, Takayama T, Miyagawa S, Yamamoto J, ljichi M, et al. Adjuvant oral uracil-tegafur with leucovorin for colorectal cancer liver metastases: a randomized controlled trial. PloS one. 2016;11:e0162400.

28. Mise Y, Aloia TA, Brudvik KW, Schwarz L, Vauthey JN, Conrad C. Parenchymal-sparing hepatectomy in colorectal liver metastasis improves salvageability and survival. Ann surg. 2016;263:146-52.
29. Torzilli G, Procopio F, Botea F, Marconi M, Del Fabbro D, Donadon M, et al. One- stage ultrasonographically guided hepatectomy for multiple bilobar colorectal metastases: a feasible and effective alternative to the 2-stage approach. Surgery. 2009;146:60-71.

30. Gold JS, Are C, Kornprat P, Jarnagin WR, Gonen M, Fong Y, et al. Increased use of parenchymal-sparing surgery for bilateral liver metastases from colorectal cancer is associated with improved mortality without change in oncologic outcome: trends in treatment over time in 440 patients. Ann surg. 2008;247:109-17.

31. Matsuki R, Mise $Y$, Saiura A, Inoue $Y$, Ishizawa T, Takahashi Y. Parenchymalsparing hepatectomy for deep-placed colorectal liver metastases. Surgery. 2016;160:1256-63.

32. Otsubo T, Kobayashi S, Sano K, Misawa T, Ota T, Katagiri S, et al. Safetyrelated outcomes of the Japanese Society of Hepato-Biliary-Pancreatic Surgery board certification system for expert surgeons. J Hepatobiliary Pancreat Sci. 2017;24:252-61.

33. Finks JF, Osborne NH, Birkmeyer JD. Trends in hospital volume and operative mortality for high-risk surgery. N Engl J Med. 2011;364:2128-37.

34. Stitzenberg KB, Sigurdson ER, Egleston BL, Starkey RB, Meropol NJ. Centralization of cancer surgery: implications for patient access to optimal care. J clin oncol. 2009;27:4671-8.

35. Birkmeyer JD, Sun Y, Wong SL, Stukel TA. Hospital volume and late survival after cancer surgery. Ann surg. 2007;245:777-83.

36. Birkmeyer JD, Siewers AE, Finlayson EV, Stukel TA, Lucas FL, Batista I, et al. Hospital volume and surgical mortality in the United States. N Engl J Med. 2002:346:1128-37.

37. Weledji EP. Centralization of liver cancer surgery and impact on multidisciplinary teams working on stage IV colorectal cancer. Oncol Rev. 2017; 11:331.

38. Vallance AE, vanderMeulen J, Kuryba A, Botterill ID, Hill J, Jayne DG, et al. Impact of hepatobiliary service centralization on treatment and outcomes in patients with colorectal cancer and liver metastases. Br J Surg. 2017;104:918-925.

39. Engstrand J, Kartalis N, Stromberg C, Broberg M, Stillstrom A, Lekberg T, et al. The impact of a hepatobiliary multidisciplinary team assessment in patients with colorectal cancer liver metastases: a population-based study. oncologist. 2017;22:1067-1074.

40. Krell RW, Reames BN, Hendren S, Frankel TL, Pawlik TM, Chung M, et al. Surgical referral for colorectal liver metastases: a population-based survey. Ann surg oncol. 2015;22:2179-94.

41. Chang CM, Yin WY, Wei CK, Lee CH, Lee CC. The combined effects of hospital and surgeon volume on short-term survival after hepatic resection in a population-based study. PloS one. 2014;9:e86444.

42. Jones RP, Vauthey JN, Adam R, Rees M, Berry D, Jackson R, et al. Effect of specialist decision-making on treatment strategies for colorectal liver metastases. Br J Surg. 2012;99:1263-9.

43. Torzilli G, Vigano L, Gatti A, Costa G, Cimino M, Procopio F, et al. Twelveyear experience of "radical but conservative" liver surgery for colorectal metastases: impact on surgical practice and oncologic efficacy. HPB (Oxford). 2017;19:775-84.

44. Zimmitti G, Roses RE, Andreou A, Shindoh J, Curley SA, Aloia TA, et al. Greater complexity of liver surgery is not associated with an increased incidence of liver-related complications except for bile leak: an experience with 2,628 consecutive resections. J Gastrointest Surg. 2013;17:57-64; discussion p 64-55.

45. Imamura $H$, Seyama $Y$, Kokudo N, Maema A, Sugawara $Y$, Sano $K$, et al. One thousand fifty-six hepatectomies without mortality in 8 years. Arch Surg. 2003:138:1198-206 discussion 1206

\section{Publisher's Note}

Springer Nature remains neutral with regard to jurisdictional claims in published maps and institutional affiliations. 